\title{
Exercise-induced ventricular arrhythmias: analysis of predictive factors in a population with sleep disorders
}

\author{
Arritmia ventricular esforço-induzida: análise dos fatores preditores em uma população \\ com queixas de sono
}

Fatima Dumas Cintra ${ }^{1}$, Marcia Regina Pinho Makdisse ${ }^{2}$, Wercules Antônio Alves de Oliveira ${ }^{3}$, Camila Furtado
Rizzi $^{4}$, Francisco Otávio de Oliveira Luiz ${ }^{5}$, Sergio Tufik ${ }^{6}$, Angelo Amato Vincenzo de Paola ${ }^{7}$, Dalva Poyares

\begin{abstract}
Objective: To assess the prevalence of ventricular arrhythmias induced by exercise in a population with sleep disorders and to analyze the triggering factors. Methods: Patients were consecutively selected from the database of the Sleep Clinic of Universidade Federal de São Paulo. All subjects were submitted to basal polysomnography, blood sample collection, physical examination, 12-lead ECG, spirometry, cardiorespiratory exercise study on a treadmill, and echocardiogram. The Control Group was matched for age and gender. Results: A total of 312 patients were analyzed. Exercise-induced ventricular arrhythmia was observed in $7 \%$. The aortic diameter was larger $(3.44 \pm 0.30,3.16 \pm 0.36, p=0.04)$ and the minimal saturation was lower $(92.75 \pm 3.05,95.50 \pm 1.73, p=0.01)$ in the ventricular arrhythmia group when compared to controls, respectively. After correction of the aortic root to body surface, there was only a trend to a larger diameter being associated with the emergence of arrhythmia. Conclusions: Exercise-induced ventricular arrhythmia was observed in $7 \%$ of sample and it was associated with lower oxygen saturation during exercise.
\end{abstract}

Keywords: Arrhythmias, Cardiac; Arrhythmias, cardiac/etiology; Arrhythmias, cardiac/epidemiology; Echocardiography, stress; Exercise test; Sleep apnea syndromes; Polysomnography; Causality; Sleep disorders; Sleep disorders/epidemiology; Anoxia

\section{RESUMO}

Objetivo: Avaliara prevalência de arritmias ventriculares esforço-induzidas em uma população com distúrbios do sono e determinar seus fatores desencadeantes. Métodos: Foram selecionados consecutivamente pacientes do banco de dados da Clínica de Sono que foram submetidos à polissonografia basal por queixas de sono. Foi realizada coleta de sangue, seguida de avaliação clínica, eletrocardiograma de 12 derivações, espirometria, teste cardiopulmonar e ecocardiograma. 0 Grupo Controle foi formado por pacientes que não desenvolveram arritmias durante 0 esforço, pareados por sexo e idade. Resultados: Foram selecionados 320 e analisados 312 pacientes. Um total de 7\% deles desenvolveram arritmia ventricular durante 0 teste cardiopulmonar. 0 diâmetro da aorta foi maior $(3.44 \pm 0.30,3.16 \pm 0.36, p=0.04)$ e a saturação mínima observada durante 0 esforço foi menor $(92.75 \pm 3.05,95.50 \pm 1.73$, $p=0.01)$ no grupo com arritmia quando comparado ao controle, respectivamente. Após correção do diâmetro de raiz da aorta para a superfície corpórea, houve apenas tendência de associação entre maior diâmetro e aparecimento de arritmia. Conclusões: 0 aparecimento de arritmia ventricular induzida pelo esforço foi observado em $7 \%$ da amostra e associado à menor saturação de oxigênio durante 0 exercício. Houve tendência de maior diâmetro da raiz de aorta nesse grupo.

Descritores: Arritmias cardíacas; Arritmias cardíacas/etiologia; Arritmias cardíacas/epidemiologia; Ecocardiografia sob estresse; Teste

\footnotetext{
Study carried out at Universidade Federal de São Paulo - UNIFESP, São Paulo (SP), Brazil; Centro Einstein de Arritmias Cardíacas do Hospital Israelita Albert Einstein - HIAE, São Paulo (SP), Brazil.

PhD in Sciences; Physician of the Cardiac Arrhythmia Center - Hospital Israelita Albert Einstein - HIAE; Researcher of the Division of Spleeping and Cardiology Medicine at Universidade Federal de São Paulo - UNIFESP, São Paulo (SP), Brazil.

2 PhD in Sciences; Physician of the Cardiology Program - Hospital Israelita Albert Einstein - HIAE; Coordinator of the Interdisciplinary Sector for Prevention of Vascular Diseases at Department of Preventive Medicine - Universidade Federal de São Paulo - UNIFESP, São Paulo (SP), Brazil.

${ }^{3} \mathrm{PhD}$; Physician of the Echocardiography Department at Hospital Israelita Albert Einstein - HIAE, São Paulo (SP), Brazil.

${ }^{4} \mathrm{PhD}$; Physical therapist at Instituto do Sono, São Paulo (SP), Brazil.

${ }^{5} \mathrm{MD}$; Department of Ergometry at Hospital Israelita Albert Einstein - HIAE, São Paulo (SP), Brazil.

${ }^{6} \mathrm{PhD}$; Full professor at Department of Psychobiology of Universidade Federal de São Paulo - UNIFESP, São Paulo (SP), Brazil.

7 PhD in Sciences; Physician of the Cardiac Arrhythmia Center - Hospital Israelita Albert Einstein - HIAE; Head of the Department of Medicine - Universidade Federal de São Paulo UNIFESP; São Paulo (SP), Brazil.

${ }^{8}$ Postdoctorate degree; Lecturer at the Department of Psychobiology of Universidade Federal de São Paulo - UNIFESP, São Paulo (SP), Brazil.

Corresponding author: Fatima Dumas Cintra - Avenida Albert Einstein, 627, Cons. 1317, 13²andar - Jardim Leonor - CEP 05652000 - São Paulo (SP), Brasil - e-mail: fatimacintra@interair.com.br

Received on June 14, 2009 - Accepted on Dec 18, 2009
} 
de esforço; Síndromes da apneia do sono; Polissonografia; Causalidade; Transtornos do sono; Transtornos do sono/epidemiologia; Anóxia

\section{INTRODUCTION}

The physiological changes occurring with exercise may precipitate exercise-induced ventricular arrhythmias (EIVA) $)^{(1)}$. The clinical significance of EIVA seems to be related to the baseline heart disease ${ }^{(2)}$. Individuals with coronary artery disease who develop ventricular arrhythmia during exercise present worse prognosis ${ }^{(3-4)}$. The occurrence of this type of arrhythmia in individuals without structural cardiac disease presents conflicting results in the medical literature ${ }^{(5-6)}$.

Recently, changes in the amount and quality of sleep are being associated with higher cardiovascular mortality $\operatorname{rates}^{(7)}$. Obstructive sleep apnea (OSA) is related to the emergence of heart failure ${ }^{(8-9)}$, cardiac $\operatorname{arrhythmias}^{(10)}$, metabolic syndrome ${ }^{(11)}$, dyslipidemia ${ }^{(12)}$ and even cerebrovascular accident ${ }^{(13)}$. The relation between sleep apnea and high blood pressure (HBP) is the most studied one; it is estimated that $40 \%$ of patients with HBP present undiagnosed and untreated associated $\mathrm{OSA}^{(14)}$. The amount of sleep also seems to be essential for maintaining cardiovascular integrity. Few hours of sleep is related to higher cardiovascular mortality ${ }^{(15)}$.

The relation between EIVA and sleep disorders has not been established, and loss of sleep integrity may help triggering this type of arrhythmia in patients with sleep abnormalities.

\section{OBJECTIVE}

To evaluate the prevalence of EIVA in a population of individuals with sleep disorders and establish the predicting factors of EIVA in this group of patients.

\section{METHODS}

\section{Population}

Patients were consecutively selected from the database of the Sleep Clinic, at the Universidade Federal de São Paulo (UNIFESP), from March 2008 to March 2009, who underwent baseline polysomnography due to sleep abnormalities (snoring, inefficient sleep, difficulty to initiate or maintain sleep, excessive daytime somnolence or periodical leg movements during sleep). The inclusion criteria were age over 30 years, sedentary lifestyle, ability to undergo a treadmill stress test and absence of recent hospitalization or change of drug treatment. The exclusion criteria were individuals with body mass index higher than $40 \mathrm{~kg} / \mathrm{m}^{2}$, chronic pulmonary disease based on the spirometry data and defined as FEV1/FVC $<0.7^{(16)}$. Past history of asthmatic bronchitis, smoking, Class III or IV heart failure (New York Heart Association), unstable angina, valvular heart disease, severe arrhythmias at rest, atrial fibrillation, uncontrolled systemic arterial hypertension, renal disease, musculoskeletal disease and pregnancy. An apnea-hypopnea index higher than 5 was considered as a diagnosis of OSA.

All individuals were instructed to come to the clinic after an 8-hour fasting and avoid the use of coffee and cigarette on the day before evaluation. Blood was drawn around 8:00 a.m., followed by breakfast and clinical evaluation, 12-lead electrocardiogram, spirometry, treadmill symptom-limited maximum cardiopulmonary exercise test and bidimensional echocardiogram with color Doppler. The Control Group included patients who did not develop EIVA, paired for sex and age. The study was approved by the Ethics Committee of UNIFESP (CEP: 1546/05)

\section{Polysomnography}

Polysomnography was carried out by the digital system EMBLA ${ }^{\circledR}$ (17 channels, Medicare Medical Devices). The following variables were monitored: electroencephalogram (EEG) (4 channels C3-A2, C4-A1, O1-A2, O2-A1), electrooculogram (two channels: LOC -A2, ROC-A1), electromyogram (two channels: submentonian and anterior tibial muscles), electrocardiogram (one modified DII channel), snoring and body position. Nasal flow was monitored with the use of a pressure transducer. Respiratory stress was monitored with abdominal and thoracic sensors. Arterial oxygen saturation and pulse were recorded with a pulse oximeter $\left(\right.$ Nonin $^{\circledR}$, model 9500, Plymouth, USA). All polysomnograms were classified by a skilled polysomnography technologist who followed the sleep study guidelines ${ }^{(17)}$ and reviewed by a sleep specialist physician. Awakenings were defined through the task force of the American Sleep Disorders Association ${ }^{(18)}$ and the respiratory events were defined by the American Academy of Sleep Medicine ${ }^{(19)}$.

\section{Laboratory evaluation}

Thirty milliliters of blood were drawn by venipuncture. The following plasma and serum variables were analyzed: complete blood count, sodium, potassium, urea, creatinine, glucose, total cholesterol and fractions, triglycerides and uric acid.

\section{Cardiopulmonary exercise testing}

The test was performed in a room with adequate temperature conditions and equipped with 
cardiopulmonary resuscitation material (ErgoPC13, Micromed $^{\circledR}$, Brasília, Brazil). During the exercise, the following parameters were monitored: 12-lead electrocardiogram, pulse oximetry $\left(\operatorname{Nonin}^{\circledR}{ }^{\circledR}\right.$, model 9500 , Plymouth, USA), blood pressure and measurements of breathing to breathing of respiratory parameters: oxygen consumption $\left(\mathrm{VO}_{2}\right)$, carbon dioxide production $\left(\mathrm{VCO}_{2}\right)$, minute ventilation (VE), respiratory rate (RR), tidal volume (Vt) through a mask (Vista CPX ${ }^{\circledR}$, Vacumed, Ventura, CA, USA) after calibration. The test was carried out in a protocol ramp treadmill, taking into account sex and age. All tests were supervised by a cardiologist and a physical therapist. Blood pressure was measured at baseline and every three minutes during exercise and recovery. The test was interrupted if diastolic blood pressure exceeded $120 \mathrm{mmHg}$ in normotensive individuals or $140 \mathrm{mmHg}$ in hypertensive individuals, or if systolic blood pressure was over $260 \mathrm{mmHg}$, symptoms of chest pain, syncope or presyncope, ischemic abnormalities in ECG, nonsustained ventricular tachycardia or second or third degree atrioventricular block.

\section{Echocardiographic exam}

All participants underwent bidimensional echocardiogram (iE33 ${ }^{\circledR}$, Philips Electronics, Netherlands) before the cardiopulmonary test. All exams were performed by a skilled echocardiographist who was blinded to the cardiopulmonary test result.

\section{Spirometry}

Pulmonary function test was performed with a computed spirometer KoKo spirometer ${ }^{\circledR}$ (Pulmonary Data Service Instrumentation, Inc., Louisville, KY, USA) according to recommendations from the American College of Chest Physicians ${ }^{(20)}$ to exclude patients with pulmonary disease. The system was calibrated with a $3 \mathrm{~L}$ syringe in different flows at least once a day. All measurements were performed in sitting position. The forced expiratory volume in one minute (FEV1), forced vital capacity (FVC), and the FEV1/FVC ratio was measured in each participant and recorded in absolute values and predicted percentage. All measurements were performed by skilled technologists. No bronchodilator was used during the evaluation.

\section{Statistical analysis}

The variables were represented as means and standard deviations. Shapiro-Wilk normality test was performed for all baseline parameters. Patients with EIVA were compared with ANOVA and $\chi^{2}$ test. $\mathrm{P}$ values $<0.05$ were considered significant. Statistical analysis was performed using the Statistic 8.0 software.

\section{RESULTS}

A total of 320 patients from the database of the Sleep Clinic at Universidade Federal de São Paulo (UNIFESP) were selected. Four individuals were excluded due to hypertensive crisis during assistance, two patients were excluded due to musculoskeletal abnormalities that precluded the performance of cardiopulmonary test, one patient due to obesity and one pregnant patient. A total of 312 participants was evaluated. Table 1 shows the features of the population studied. Sixty percent of patients presented OSA, 37\% had high blood pressure and $12 \%$ had diabetes. Seven per cent developed EIVA during the cardiopulmonary test (Figure 1). Isolated ventricular ectopy frequent during the exercise was the most frequent presentation of EIVA. We observed five cases of coupled ventricular ectopy and one case of nonsustained ventricular tachycardia with three beats.

Table 1. Characteristics of the population

\begin{tabular}{lc}
\hline Characteristics & Participants $(\mathbf{n}=\mathbf{3 1 2})$ \\
\hline Age (years) & $50.74 \pm 7.51$ \\
Male $(\mathrm{n})$ & $173(55.4 \%)$ \\
Body mass index $\left(\mathrm{kg} / \mathrm{m}^{2}\right)$ & $27.27 \pm 4.08$ \\
Sleep obstructive apnea & 60 \\
High blood pressure (\%) & 37 \\
Diabetes (\%) & 12 \\
Caucasian (\%) & 89 \\
EIVA (\%) & 7 \\
\hline
\end{tabular}

EIVA: exercise-induced ventricular arrhythmias

Patients who developed EIVA were paired with the Control Group and the clinical parameters in both groups are shown in Table 2. Aortic diameter was larger in the EIVA group when compared to the Control Group $(3.44 \pm 0.30,3.16 \pm 0.36$, respectively, $p=$ $0.04)$. The other echocardiographic parameters did not

Table 2. Clinical characteristics of the EIVA and control groups

\begin{tabular}{lccc}
\hline Clinical characteristics & EIVA $(\mathbf{n}=\mathbf{1 8})$ & Control $(\mathbf{n}=\mathbf{1 8})$ & $\mathbf{p}$-value \\
\hline Age (years) & $53.27 \pm 8.58$ & $53.05 \pm 8.62$ & 0.94 \\
Males $(\mathrm{n})$ & 72 & 72 & 0.99 \\
Body mass index $\left(\mathrm{kg} / \mathrm{m}^{2}\right)$ & $28.52 \pm 3.61$ & $29.33 \pm 5.37$ & 0.60 \\
Abdominal circumference $(\mathrm{cm})$ & $95.04 \pm 11.25$ & $94.15 \pm 16.18$ & 0.89 \\
Hip circumference (cm) & $102.68 \pm 6.63$ & $103.77 \pm 7.93$ & 0.75 \\
High blood pressure (\%) & 12 & 9 & 0.74 \\
Diabetes (\%) & 1 & 1 & 0.82 \\
\hline
\end{tabular}

EIVA: exercise-induced ventricular arrhythmias 

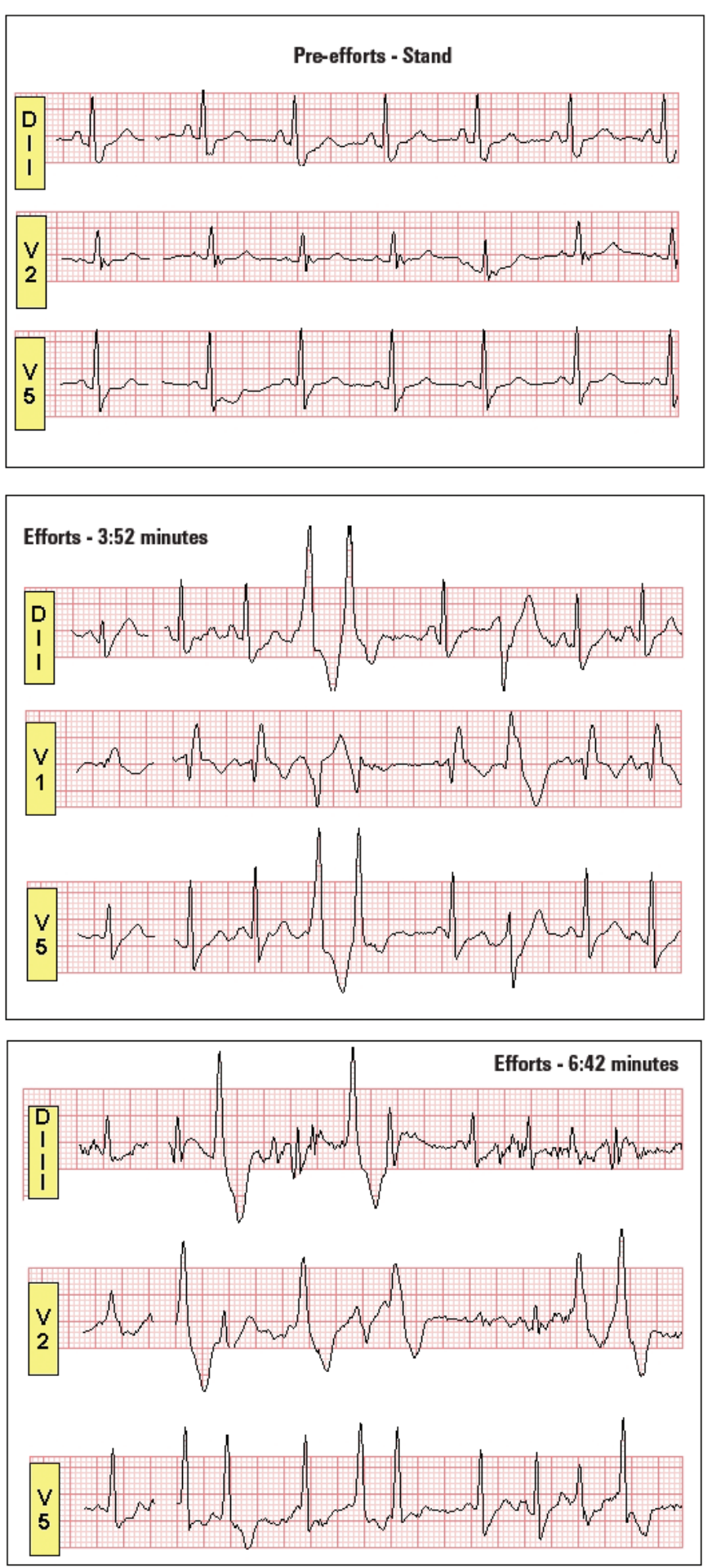

Figure 1. Isolated ventricular ectopy and coupled induced during cardiopulmonary test

show differences between the groups (Table 3). After correction of the aortic diameter to the body surface, no more statistical differences were observed between the EIVA and control groups $(1.82 \pm 0.19,1.64 \pm 0.30$, respectively, $\mathrm{p}=0.08$ ).
Table 3. Echocardiographic findings of ElVA and control groups

\begin{tabular}{lccc}
\hline Echocardiographic findings & EIVA $(\mathbf{n}=\mathbf{1 8})$ & Control $(\mathbf{n}=\mathbf{1 8})$ & $\mathbf{p}$-value \\
\hline Aortic root diameter $(\mathrm{mm})$ & $3.44 \pm 0.30$ & $3.16 \pm 0.36$ & 0.04 \\
Left atrium diameter $(\mathrm{mm})$ & $3.86 \pm 0.21$ & $3.78 \pm 0.40$ & 0.52 \\
Right ventricle diameter $(\mathrm{mm})$ & $2.12 \pm 0.34$ & $2.01 \pm 0.20$ & 0.34 \\
Intraventricular septum $(\mathrm{mm})$ & $0.92 \pm 0.07$ & $0.95 \pm 0.17$ & 0.63 \\
Left ventricle posterior wall $(\mathrm{mm})$ & $0.91 \pm 0.30$ & $0.90 \pm 0.14$ & 0.76 \\
Left ventricle diastolic diameter $(\mathrm{mm})$ & $4.98 \pm 0.45$ & $4.76 \pm 0.29$ & 0.19 \\
Left ventricle systolic diameter $(\mathrm{mm})$ & $3.16 \pm 0.59$ & $2.93 \pm 0.15$ & 0.26 \\
Left ventricle ejection fraction & $63.01 \pm 8.07$ & $68.00 \pm 4.35$ & 0.14 \\
\hline
\end{tabular}

EIVA: exercise-induced ventricular arrhythmias

The laboratory parameters analyzed did not show differences between groups (Table 4). Sleep structure and the apnea/hypopnea index were similar in both groups (Table 5). Hemodynamic behavior during exercise is shown in Table 6. Spirometric data are shown in Table 7. Although baseline saturation is similar in the EIVA and control groups $(96.50 \pm 1.84,97.33 \pm 1.49$, respectively, $\mathrm{p}=0.25)$, the minimum saturation observed during the exercise was lower in the group developing ventricular arrhythmia as compared to the Control Group (92.75 \pm $3.05,95.50 \pm 1.73$, respectively, $\mathrm{p}=0.01$ ).

Table 4. Laboratory assessment of the EIVA and control groups

\begin{tabular}{lccc}
\hline Laboratory parameters & EIVA $(\mathbf{n}=\mathbf{1 8})$ & Control $(\mathbf{n}=\mathbf{1 8})$ & p-value \\
\hline Hemoglobin (g/dl) & $15.5 \pm 2.05$ & $15.41 \pm 1.02$ & 0.80 \\
Hematocrit (g/dl) & $44.43 \pm 15.05$ & $44.62 \pm 7.05$ & 0.78 \\
Glucose (mg/dl) & $108.38 \pm 17.14$ & $104.43 \pm 16.62$ & 0.45 \\
Total cholesterol (mg/dl) & $210.54 \pm 43.23$ & $213.90 \pm 40.32$ & 0.45 \\
Low density lipoprotein (mg/dl) & $129.86 \pm 35.95$ & $129.64 \pm 32.84$ & 0.95 \\
High density lipoprotein (mg/dl) & $56.25 \pm 11.43$ & $56.80 \pm 14.23$ & 0.87 \\
(mg/dl) & & & \\
Very low density lipoprotein & $27.47 \pm 16.43$ & $26.69 \pm 12.53$ & 0.66 \\
(mg/dl) (mg/dl) & & & \\
Triglycerides (mg/dl) & $149.55 \pm 91.03$ & $145.02 \pm 86.98$ & 0.62 \\
Creatinine (mg/dl) & $0.94 \pm 0.17$ & $0.91 \pm 0.15$ & 0.54 \\
Urea (mg/dl) & $34.94 \pm 6.84$ & $36.17 \pm 7.58$ & 0.61 \\
Sodium (mmol/) & $140.77 \pm 1.92$ & $140.11 \pm 1.99$ & 0.32 \\
Potassium (mmol/) & $4.21 \pm 0.46$ & $4.23 \pm 0.29$ & 0.88 \\
Uric acid (mg/dl) & $5.25 \pm 1.06$ & $5.54 \pm 1.41$ & 0.49 \\
\hline
\end{tabular}

EIVA: exercise-induced ventricular arrhythmias

Table 5. Sleep architecture in EIVA and control groups

\begin{tabular}{lccc}
\hline Sleep architecture & EIVA $(\mathbf{n}=\mathbf{1 8})$ & Control $(\mathbf{n}=\mathbf{1 8})$ & $\mathbf{p}$-value \\
\hline Total sleep time (min) & $362.20 \pm 61.37$ & $353.02 \pm 85.46$ & 0.66 \\
Number of arousals & $90.93 \pm 73.16$ & $106.39 \pm 100.99$ & 0.54 \\
Stage 1 percentage & $4.87 \pm 3.64$ & $4.77 \pm 5.01$ & 0.94 \\
Stage 2 percentage & $51.78 \pm 7.66$ & $56.63 \pm 12.59$ & 0.13 \\
Sleep onset latency percentage & $22.41 \pm 7.52$ & $20.01 \pm 11.95$ & 0.43 \\
REM sleep percentage & $18.41 \pm 6.45$ & $19.78 \pm 10.51$ & 0.62 \\
Sleep efficiency (\%) & $81.45 \pm 11.37$ & $82.99 \pm 11.10$ & 0.59 \\
Minimum saturation & $86.81 \pm 4.15$ & $85.15 \pm 9.08$ & 0.47 \\
Apnea/hypopnea index & $15.94 \pm 12.85$ & $18.67 \pm 21.71$ & 0.60 \\
\hline
\end{tabular}

EIVA: exercise-induced ventricular arrhythmias; REM: rapid eye movement. 
Table 6. Homodynamic behavior in EIVA and control groups

\begin{tabular}{lccc}
\hline Homodynamic behavior & EIVA $(\mathbf{n}=\mathbf{1 8})$ & Control $(\mathbf{n}=\mathbf{1 8})$ & $\mathbf{p}$-value \\
\hline $\begin{array}{l}\text { Baseline systolic pressure } \\
\text { (mmHg) }\end{array}$ & $127.77 \pm 16.28$ & $128.82 \pm 15.36$ & 0.84 \\
$\begin{array}{l}\text { Baseline diastolic pressure } \\
\text { (mmHg) }\end{array}$ & $85.00 \pm 10.43$ & $83.52 \pm 11.14$ & 0.68 \\
$\begin{array}{l}\text { Peak systolic pressure }(\mathrm{mmHg}) \\
\text { Peak diastolic pressure }(\mathrm{mmHg})\end{array}$ & $90.27 \pm 10.61$ & $85.58 \pm 8.63$ & 0.39 \\
$\begin{array}{l}\text { Recovery systolic pressure } \\
\text { (mmHg) }\end{array}$ & $185.55 \pm 35.53$ & $177.64 \pm 26.81$ & 0.48 \\
$\begin{array}{l}\text { Recovery diastolic pressure } \\
\text { (mmHg) }\end{array}$ & $88.61 \pm 9.23$ & $82.64 \pm 8.31$ & 0.24 \\
$\begin{array}{l}\text { Baseline heart rate }(\mathrm{bpm}) \\
\text { Peak heart rate (bpm) }\end{array}$ & $76.27 \pm 7.89$ & $77.70 \pm 12.19$ & 0.68 \\
Recovery heart rate $(\mathrm{bpm})$ & $124.35 \pm 21.69$ & $126.58 \pm 22.01$ & 0.76 \\
\hline
\end{tabular}

Table 7. Ergospirometric data of EIVA and control groups

\begin{tabular}{lccc}
\hline Ergospirometric data & EIVA $(\mathbf{n}=\mathbf{1 8})$ & Control $(\mathbf{n}=\mathbf{1 8})$ & $\mathbf{p}$-value \\
\hline VO2 $(\mathrm{ml} / \mathrm{kg} / \mathrm{min})$ & $30.44 \pm 9.49$ & $33.39 \pm 9.83$ & 0.38 \\
VCO2 $(\mathrm{ml} / \mathrm{Kg} / \mathrm{min})$ & $31.47 \pm 10.90$ & $34.19 \pm 10.07$ & 0.52 \\
O2 pulse & $15.13 \pm 3.70$ & $15.96 \pm 4.26$ & 0.60 \\
R & $1.03 \pm 0.12$ & $1.03 \pm 0.06$ & 0.97 \\
VENO2 & $25.67 \pm 3.61$ & $26.08 \pm 2.83$ & 0.75 \\
VENCO2 & $24.81 \pm 2.07$ & $25.52 \pm 2.96$ & 0.47 \\
Peak VE & $79.82 \pm 25.39$ & $82.00 \pm 34.43$ & 0.85 \\
VVM & $138.97 \pm 34.84$ & $107.62 \pm 40.92$ & 0.06 \\
Baseline saturation & $96.50 \pm 1.84$ & $97.33 \pm 1.49$ & 0.25 \\
Peak saturation & $92.75 \pm 3.05$ & $95.50 \pm 1.73$ & 0.01 \\
\hline
\end{tabular}

EIVA: exercise-induced ventricular arrhythmias

\section{DISCUSSION}

This is the first study that evaluates the occurrence of exercise-induced ventricular arrhythmia in a population with no heart disease, but with a high risk of heart disease, such as individuals with sleep disorders, especially OSA. The main factor related to the emergence of this type of arrhythmia during exercise is saturation drop. The relation between hypoxia and occurrence of ventricular arrhythmia is being studied. Recently, the MrOS study ${ }^{(21)}$ evaluated the association of sleep respiratory disorder and the occurrence of nocturnal atrial fibrillation/flutter and complex ventricular ectopy in elderly men. The percentage of sleep time with arterial oxygen saturation lower than $90 \%$ was related to the occurrence of complex ventricular ectopy, and those in the categories with higher hypoxia presented a higher risk of this type of arrhythmia $(\mathrm{OR}=1.62$; $95 \% \mathrm{CI}=1.23-2.14)$. Hansel et al. ${ }^{(22)}$ evaluated the role of hypoxia caused by maximum voluntary apnea on the occurrence of cardiac arrhythmias. After voluntary interruption of breathing for a mean period of $281 \pm$ 73 seconds, there was a significant drop in oxygen saturation and heart rate and the emergence of cardiac arrhythmias (ventricular and atrial ectopies) in $77 \%$ of the participants, which were directly related to duration of apnea. Cripps et al. ${ }^{(23)}$ evaluated the occurrence of severe arrhythmias and nocturnal hypoxia in individuals with left ventricular dysfunction, showing a correlation between the presence of arrhythmias and episodes of hypoxemia (episodes of hypoxemia in patients with severe arrhythmias occurred in 17 out of 20 subjects ( $85 \%$ ) versus 3 out of 14 participants who did not present events of arrhythmias $(\mathrm{p}<0.002)$. The authors suggest that initiatives to minimize nocturnal desaturation could contribute to the treatment of individuals with left ventricular dysfunction.

The mechanisms involved in the emergence of ventricular arrhythmias during exercise are not totally established. Data from this study suggest that exercise induces hypoxia in a subgroup of patients and ventricular arrhythmia is possibly secondary to hypoxemia ${ }^{(20-23)}$. In this context, it would be important to determine the individuals prone toexercise-induced hypoxemia. Baseline spirometric features were similar in the two groups with and without EIVA. However, Ruf and Hebestreit ${ }^{(24)}$ demonstrated the occurrence of EIVA related to lower baseline oxygen saturation and at the peak exercise and FEV1 $<50 \%$ of the value predicted for patients with cystic fibrosis. These conflicting data in the literature are possibly related to different populations analyzed and, in this study, we excluded patients with heart failure, respiratory failure, renal failure and smokers.

Increased aortic root diameter was related to the occurrence of EIVA. After correction for body surface, we observed only a trend $(p=0.08)$ to the association between aortic root and ventricular arrhythmia. However, this data should be considered and it may be related to possible inflammatory and oxidative mechanisms that would lead to greater susceptibility of exercise-mediated hypoxemia and ventricular arrhythmia. Although body surface, age and sex are the main determinants of the thoracic aorta diameter, aortic atherosclerosis related to inflammation also seems to be a minor factor contributing to aortic dilation ${ }^{(25-26)}$.

Therefore, baseline evaluation including spirometry, laboratory evaluation, polysomnography and echocardiogram failed to discriminate the group of individuals who are at risk of developing EIVA during exercise. It seems to be difficult to identify such patients by using only diagnostic tools at rest. The use of pulse oximetry may be considered a limitation to the study, since nowadays there are brain devices with sensors located in the frontal region which better evaluate the saturation pattern during exercise. Additionally, the evaluated sample was represented in its vast majority by patients with OSA $(60 \%)$, and it was difficult to extrapolate these data to other sleep disorders such as insomnia and restless legs syndrome, among others. 


\section{CONCLUSIONS}

EIVA occurred in $7 \%$ of sample and it was associated with lower oxygen saturation during exertion. Sleep structure and the apnea/hypopnea index were not predictors of the occurrence of ventricular arrhythmia. There was a trend to a larger diameter of the aortic root in the group with EIVA when compared to the Control Group.

\section{ACKNOWLEDGEMENTS}

State of Sao Paulo Research Foundation (FAPESP) and Associação Fundo de Incentivo à Psicofarmacologia (AFIP), São Paulo (SP), Brazil.

\section{REFERENCES}

1. Udall JA, Ellestad MH. Predictive implications of ventricular premature contractions associated with treadmill stress testing. Circulation. 1977;56(6):985-9.

2. Marieb MA, Beller GA, Gibson RS, Lerman BB, Kaul S. Clinical relevance of exercise-induced ventricular arrhythmias in suspected coronary artery disease. Am J Cardiol. 1990;66(2):172-8.

3. Califf RM, McKinnis RA, McNeer JF, Harrell FE Jr, Lee KL, Pryor DB, et al. Prognostic value of ventricular arrhythmias associated with treadmill exercise testing in patients studied with cardiac catheterization for suspected ischemic heart disease. J Am Coll Cardiol. 1983;2(6):1060-7.

4. Nair CK, Thomson W, Aronow WS, Pagano T, Ryschon K, Sketch MH. Prognostic significance of exercise-induced complex ventricular arrhythmias in coronary artery disease with normal and abnormal left ventricular ejection fraction. Am J Cardiol. 1984;54(8):1136-8.

5. Jouven X, Zureik M, Desnos M, Courbon D, Ducimetière P. Long-term outcome in asymptomatic men with exercise-induced premature ventricular depolarizations. N Engl J Med. 2000;343(12):826-33.

6. Busby MJ, Shefrin EA, Fleg JL. Prevalence and long-term significance of exercise-induced frequent or repetitive ventricular ectopic beats in apparently healthy volunteers. J Am Coll Cardiol. 1989;14(7):1659-65.

7. Marin JM, Carrizo SJ, Vicente E, Agusti AG. Long-term cardiovascular outcomes in men with obstructive sleep apnoea-hypopnoea with or without treatment with continuous positive airway pressure: an observational study. Lancet. 2005;365(9464):1046-53.

8. Javaheri S, Parker TJ, Liming JD, Corbett WS, Nishiyama H, Wexler L, et al. Sleep apnea in 81 ambulatory male patients with stable heart failure: types and their prevalences, consequences, and presentations. Circulation. 1998;97(21):2154-9.

9. Shahar E, Whitney CW, Redline S, Lee ET, Newman AB, Javier Nieto F, et al. Sleep-disordered breathing and cardiovascular disease: cross-sectional results of the Sleep Heart Health Study. Am J Respir Crit Care Med. 2001;163(1):19-25.
10. Guilleminault C, Connoly SJ, Winkle RA. Cardiac arrhythmia and conduction disturbances during sleep in 400 patients with sleep apnea syndrome. Am J Cardiol. 1983;52(5):490-4.

11. Alam I, Lewis K, Stephens JW, Baxter JN. Obesity, metabolic syndrome and sleep apnoea: all pro-inflammatory states. Obes Rev. 2007;8(2):119-27.

12. Savransky V, Nanayakkara A, Li J, Bevans S, Smith PL, Rodriguez A, et al. Chronic Intermittent hypoxia induces atherosclerosis. Am J Respir Crit Care Med. 2007;175(12):1290-7.

13. Dziewas R, Humpert M, Hopmann B, Kloska SP, Lüdemann P, Ritter M, et al. Increased prevalence of sleep apnea in patients with recurring ischemic stroke compared with first stroke victims. J Neurol. 2005;252(11):1394-8.

14. Silverberg DS, Oksenberg A. Are sleep-related breathing disorders important contributing factors to the production of essential hypertension? Curr Hypertens Rep. 2001;3(3):209-15.

15. Gallicchio L, Kalesan B. Sleep duration and mortality: a systematic review and meta-analysis. J Sleep Res. 2009;18(2):148-58.

16. Standardization of Spirometry, 1994 Update. American Thoracic Society. Amer J Resp Care Med. 1995;152(3):1107-36.

17. Kushida CA, Littner MR, Morgenthaler T, Alessi CA, Bailey D, Coleman J Jr, et al. Practice parameters for the indications for polysomnography and related procedures: an update for 2005. Sleep. 2005;28(4):499-521. Review.

18. Polysomnography Task Force, American Sleep Disorders Association Standards of Practice Committee. Practice parameters for the indications for polysomnography and related procedures. Sleep. 1997;20(6):406-22.

19. American Academy of Sleep Medicine Task Force. Sleep-related breathing disorders in adults: recommendations for syndrome definition and measurement techniques in clinical research. Sleep. 1999;22(5):667-89.

20. American Thoracic Society. Lung function testing: selection of reference values and interpretative strategies. Am Rev Respir Dis. 1991; 144(5): 1202-18.

21. Mehra R, Stone KL, Varosy PD, Hoffman AR, Marcus GM, et al. Nocturnal Arrhythmias Across a Spectrum of Obstructive and Central Sleep-Disordered Breathing in Older Men. Outcomes of Sleep Disorders in Older Men (MrOS Sleep) Study. Arch Intern Med. 2009;169(12): 1147-55.

22. Hansel J, Solleder I, Gfroerer W, Muth CM, Paulat K, Simon P, et al. Hypoxia and cardiac arrhythmias in breath-hold divers during voluntary immersed breath-holds. Eur J Appl Physiol. 2009;105(5):673-8.

23. Cripps T, Rocker G, Stradling J. Nocturnal hypoxia and arrhythmias in patients with impaired left ventricular function. Br Heart J. 1992;68(4):382-6.

24. Ruf $K$, Hebestreit $H$. Exercise-induced hypoxemia and cardiac arrhythmia in cystic fibrosis. J Cyst Fibros. 2009;8(2):83-90.

25. Benvenuti LA, Onishi RY, Gutierrez OS, Higushi ML. Different patterns of atherosclerotic remodeling in the thoracic and abdominal aorta. Clinics. 2005;60(5):355-60.

26. Russo C, Jin Z, Rundek T, Homma S, Sacco RL, DiTullio MR. Atherosclerotic disease of the proximal aorta and the risk of vascular events in a populationbased cohort: the Aortic Plaques and Risk of Ischemic Stroke (APRIS) study. Stroke. 2009;40(7):2313-8. 